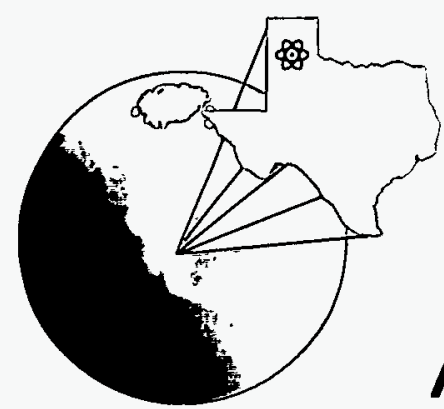

ANRCP-1999-3

January 1999

Amarillo National

Resource Center for Plutonium

A Higher Education Consortium of The Texas A\&M University System, Texas Tech University, and The University of Texas System

\title{
Application of a New Time Scale Based Low K- $\varepsilon$ Model to Natural Convection from a Semi-Infinite Vertical Isothermal Plate RECEIVED
} FFR 08 B 1999

OS.S. Sithiooran and S. Parameswaran Department of Mechanical Engineering Texas Tech University

This report was prepared with the support of the U.S. Department of Energy (DOE), Cooperative Agreement No. DE-FC04-95AL85832. However, any oplnions, findings, conclusions, or recommendations expressed herein are those of the author(s) and do not necessarlly reflect the views of DOE. This work was condueted through the Amarillo National Resource Center for Plutonium. 


\title{
AMARILLO NATIONAL RESOURCE CENTER FOR PLUTONIUM/
} A HIGHER EDUCATION CONSORTIUM

\author{
A Report on \\ Application of a New Time Scale Based Low K- $\varepsilon$ Model To \\ Natural Convection from a Semi-Infinite Vertical Isothermal Plate
}

S. Senthooran and S. Parameswaran

Department of Mechanical Engineering

Texas Tech University

Lubbock, Texas 79409

Submitted for publication to

\section{ANRC Nuclear Program}

January 1999 


\section{DISCLAIMER}

This report was prepared as an account of work sponsored by an agency of the United States Government. Neither the United States Government nor any agency thereof, nor any of their employees, makes any warranty, express or implied, or assumes any legal liability or responsibility for the accuracy, completeness, or usefulness of any information, apparatus, product, or process diselosed, or represents that its use would not infringe privately owned rights. Reference berein to any specific commercial product, process, or service by trade name, trademark, inanufacturer, or otherwise does not necessarily constitute or imply its endorsement, recom. mendation, or favoring by the United States Government or any agency thereof. The views and opinions of authors expressed herein do not necessarily state or reflect those of the United States Government or any agency thereof. 


\section{DISCLAIMER}

Portions of this document may be illegible in electronic image products. Images are produced from the best available original document. 


\section{TABLE OF CONTENTS}

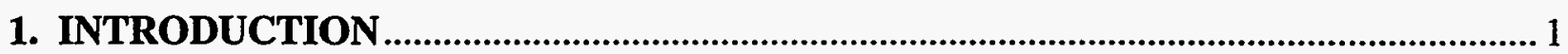

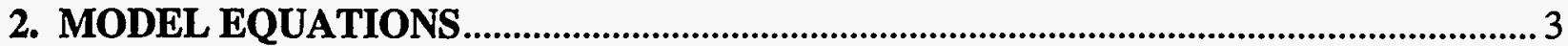

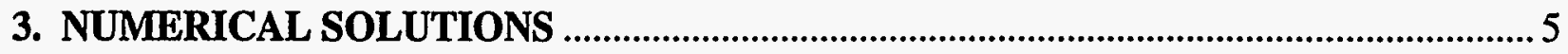

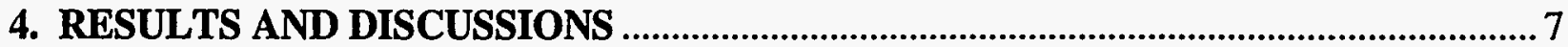

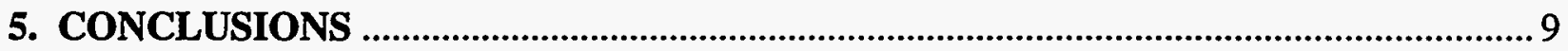

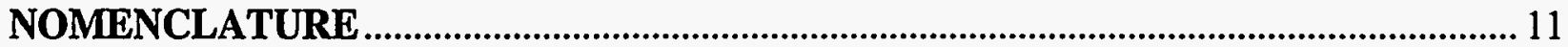

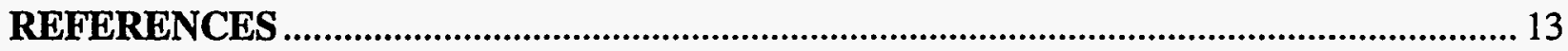




\section{LIST OF FIGURES}

Figure 1: Velocity Profile at $\mathrm{Gr}_{\mathrm{x}}=10^{12}$ (Variation of $\mathrm{u} / \mathrm{U}$ with $\eta$ )............................................15

Figure 2: Temperature Profile at $\mathrm{Gr}_{\mathrm{x}}=10^{12}$ (Variation of $\left(\mathrm{t}-\mathrm{t}_{\infty}\right) /\left(\mathrm{t}_{\mathrm{w}}-\mathrm{t}_{\infty}\right)$ with $\left.\eta\right) \ldots \ldots \ldots \ldots \ldots \ldots \ldots \ldots . . . . . . .15$

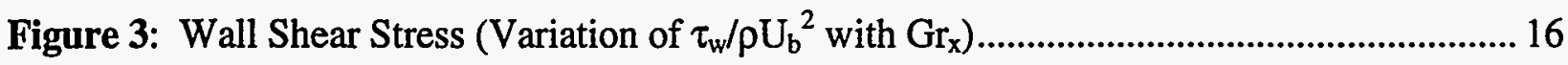

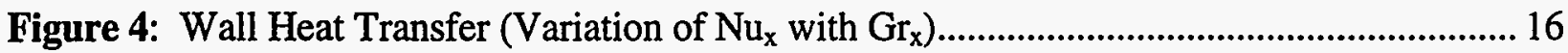




\title{
Application of a New Time Scale Based Low K- $\varepsilon$ Model To Natural Convection from a Semi-Infinite Vertical Isothermal Plate
}

\author{
S. Senthooran and S. Parameswaran \\ Department of Mechanical Engineering \\ Texas Tech University \\ Lubbock, Texas 79409
}

\begin{abstract}
The low k- $\varepsilon$ model proposed by Yang and Shih (1992) is applied to the calculation of the turbulent natural convective boundary layer over a semi-infinite, vertical, isothermal surface. Using $\mathrm{k} / \varepsilon$ as the turbulent time scale will introduce a singularity in the $\varepsilon$ equation, near the wall. This model uses a modified
\end{abstract}

turbulent time scale near the wall to eliminate this singularity. The constants in the equation for damping function are modified to produce better results for both, natural convection and forced convection. The results are compared with available experimental data and the results obtained from Chien's model and are found to be in reasonable agreement. 


\section{INTRODUCTION}

Heat transfers by natural convection from vertical isothermal surfaces have received considerable research interest since these flows are encountered in many industrial applications. The two equation $k-\varepsilon$ model is widely used to model turbulent flows. Here $\mathrm{k}$ represents the turbulent kinetic energy and $\varepsilon$ represents the dissipation rate of turbulent kinetic energy. This model is usually applied with logarithmic wall functions for velocity and temperature, to avoid the application of the $k-\varepsilon$ model in the laminar sub-layer near the wall. These wall functions only hold for forced convection flows; they do not hold for natural convection flows. Proper wall functions for natural convection flows have still not been found. Therefore low $k-\varepsilon$ model should be applied for natural convection flows, in which the calculations are performed up to the wall. The first low $k-\varepsilon$ model was proposed by Jones and Launder, which was then followed by a number of other models.

Yang and Shih proposed a new time scale based $k-\varepsilon$ model for near wall turbulence. In this model, the eddy viscosity is characterized by a turbulent velocity scale and a turbulent time scale. It uses a modified time scale near the wall such that there is no singularity in the dissipation equation near the wall. The model constants are exactly the same as those in the standard $k-\varepsilon$ model that ensures the performance of the model far from the wall. In this paper the constants in the damping function are modified to provide better results for both, natural convection and forced convection. The modified model is applied to the calculation of the turbulent natural convective boundary layer over a vertical, isothermal surface. The results are compared with available experimental data and the results obtained from Chien's model. 


\section{MODEL EQUATIONS}

The time averaged turbulent boundary layer equations for two-dimensional, incompressible buoyancy induced flow are as follows.

Continuity:

$$
\frac{\partial u}{\partial x}+\frac{\partial v}{\partial y}=0
$$

Momentum:

$$
\begin{aligned}
& u \frac{\partial u}{\partial x}+v \frac{\partial u}{\partial y}=-\frac{1}{\rho} \frac{d p}{d x}+\frac{\partial}{\partial y} \\
& \left(v+v_{t}\right) \frac{\partial u}{\partial y}+g \beta\left(t-t_{\infty}\right)
\end{aligned}
$$

Energy:

$$
u \frac{\partial t}{\partial x}+v \frac{\partial t}{\partial y}=\frac{\partial}{\partial y}\left(\frac{v}{\operatorname{Pr}}+\frac{v_{t}}{\operatorname{Pr}_{t}}\right) \frac{\partial t}{\partial y}
$$

It is assumed that the Boussinesq is valid and

$$
u \frac{\partial k}{\partial x}+v \frac{\partial k}{\partial y}=\frac{\partial}{\partial y}\left(v+\frac{v_{t}}{\sigma_{k}}\right) \frac{\partial k}{\partial y}+v_{t}\left(\frac{\partial u}{\partial y}\right)^{2}-\varepsilon
$$

the turbulent stresses are proportional to the mean velocity gradients.

$$
\begin{aligned}
& u \frac{\partial \varepsilon}{\partial x}+v \frac{\partial \varepsilon}{\partial y}=\frac{\partial}{\partial y}\left(v+\frac{v_{t}}{\sigma_{\varepsilon}}\right) \frac{\partial \varepsilon}{\partial y} \\
& +\left[c_{1 e} v_{t}\left(\frac{\partial u}{\partial y}\right)^{2}-c_{2 \varepsilon} \varepsilon\right] / T_{t}
\end{aligned}
$$

The transport equations for $\mathrm{k}$ and $\varepsilon$ are given as follows.

$\mathrm{k}$ equation:

$\varepsilon$ equation:
The time scale $\left(\mathrm{T}_{\mathrm{t}}\right)$ used in the standard $\mathrm{k}-\varepsilon$ model is $\mathrm{k} / \varepsilon$. Using this time scale up to the wall will introduce a singularity in the $\varepsilon$ equation due to vanishing $\mathrm{k}$ at the wall. Therefore near the wall this time scale has to be modified to avoid this singularity. Yang and Shih showed that the time scale near the wall should be the Kolmogorov time scale because viscous dissipation dominates near the wall. Therefore they proposed that the turbulent time scale be given by $k / \varepsilon$ away from the wall and by the Kolmogorov time scale near the wall. The time scale for the whole region could be written as

$\mathrm{T}_{\mathrm{t}}=\mathrm{k} / \varepsilon+\mathrm{T}_{\mathrm{k}}$

where $T_{k}$ is the Kolmogorov time scale and is given by

$\mathrm{T}_{\mathrm{k}}=\mathrm{c}_{\mathrm{k}}(v / \varepsilon)^{1 / 2}$

This time scale ensures the performance of the standard $k-\varepsilon$ model far from the wall since $k / \varepsilon$ is much larger than $T_{k}$ away from the wall and the model constants are the same as those in the standard k- $\varepsilon$ model. Since $k / \varepsilon$ vanishes near the wall due to the boundary condition for $k$, the time scale near the wall would be $\mathrm{T}_{\mathrm{k}}$.

Using this time scale as the turbulent time scale and $k^{1 / 2}$ as the turbulent velocity scale would give the below expression for the eddy viscosity.

$v_{t}=c_{\mu} f_{\mu} k T_{t}$

$f_{\mu}$ is the damping function, which is used to account for the wall effect and is given by

$$
f_{\mu}=\left[1-\exp \left(-a_{1} R_{y}-a_{3} R_{y}{ }^{3}-a_{5} R_{y}{ }^{5}\right)\right]^{1 / 2}
$$


where

$\mathrm{R}_{\mathrm{y}}=\mathrm{k}^{1 / 2} \mathrm{y} / \mathrm{v}$

and $a_{1}=3.0^{*} 10^{-4}, a_{2}=6.0 * 10^{-5}, a_{3}=2.0^{*} 10^{-6}$.

The suggested boundary condition for

$\varepsilon$ on the wall is:

$\varepsilon_{\mathrm{w}}=2 \mathrm{v}\left(\mathrm{dk}^{1 / 2} / \mathrm{dy}\right)^{2}$ 


\section{NUMERICAL SOLUTION}

The free convection turbulent boundary layer equations are solved for a semi-infinite isothermal flat plate. Air is the fluid considered for these calculations. The EXPRESS code, which uses the standard $k-\varepsilon$ model and the Reynolds stress model, is modified with the above low $k-\varepsilon$ model and used to for these calculations. The above governing equations are transformed from the physical coordinates $(x, y)$ into the coordinate system $(x, \eta)$ where the non-dimensional cross stream coordinate $\eta$ is defined as:

$\eta=y / \delta$.

Even though $\delta$ varies with $\mathrm{x}$, the computational domain is constrained to lie in the region:

$0 \leq \eta \leq 1$.

The control volume approach is used to discretize the governing equation. In this approach the governing partial differential equations are converted into algebraic equations by integrating them over the cells.

Since for gases and liquids with moderate Prandtl number transition to turbulent flow occurs between $\mathrm{Gr}_{\mathrm{x}}=10^{9}$ and $10^{10}$, the calculation was started at $\mathrm{Gr}_{\mathrm{x}}=10^{10}$. Profile shapes used by Eckert and Jackson are used for initial velocity and temperature profiles. These profiles are given by:

$\mathrm{u} / \mathrm{U}=(\mathrm{y} / \delta)^{1 / 7}(1-\mathrm{y} / \delta)^{4}$

$\left(t-t_{\infty}\right) /\left(t_{w}-t_{\infty}\right)=1-(y / \delta)^{1 / 7}$

where $U$ is the characteristic velocity and is given by:

$U=\left[g \beta\left(t_{w}-t_{\infty}\right) x\right]^{1 / 2}$.

At the free stream, the velocity components are set to zero, the turbulence quantities are set to a pre-set free stream values and the temperature is set to a constant value $\left(t_{\infty}\right)$. At the wall the velocity components are set to zero, the temperature is set to a constant value $\left(t_{w}\right), k$ is set to zero and $\varepsilon$ is given by Equation (11).

At each $x$ station, the system of nonlinear equations are solved using the Thomas algorithm (TDMA) and then marched downstream to the next $x$ station. 



\section{RESULTS AND DISCUSSIONS}

The results obtained from the above model are compared with the available experimental results and the results obtained by using Chien's low $k-\varepsilon$ model. Calculations are performed for $\operatorname{Pr}=0.71$ with 44 grids in the $y$ direction. The non-dimensional turbulent velocity and temperature profiles at $\mathrm{Gr}_{\mathrm{x}}=10^{12}$ are compared with the profiles obtained from Chien's model in Figure 1 and Figure 2 respectively. These profiles are plotted versus $\eta$. The velocity is normalized with the characteristic velocity $U$. The profiles are agreeing well with those obtained using Chien's model.

The distribution of wall shear stress $\tau_{\mathrm{w}}$ is shown in Figure 3. From the experimental results Tsuji and Nagano found a correlation for the turbulent shear stress. It is given by

$\tau_{\mathrm{w}} / \rho \mathrm{U}_{\mathrm{b}}{ }^{2}=0.684 \mathrm{Gr}_{\mathrm{x}}{ }^{1 / 11.9}$

The shear stress distribution is compared with the above correlation and the distribution obtained from Chien's model and found to be agreeing well.

Figure 4 shows the wall heat transfer as a function of $\mathrm{Gr}_{\mathrm{x}}$. The calculated values are compared with the values obtained from Chien's model and the best fit curve found from the experimental values. The best fit curve for $\mathrm{Nu}_{\mathrm{x}}$ for air at large $\mathrm{Gr}_{\mathrm{x}}$ is given by

$\mathrm{Nu}_{\mathrm{x}}=0.106 \mathrm{Gr}_{\mathrm{x}}^{1 / 3}$

Though the wall heat transfer calculated using Chien's model is close to the experimental values at the beginning, it is becoming too high for large $\mathrm{Gr}_{\mathrm{x}}$. The presented low $\mathrm{k}-\varepsilon$ model is under predicting the wall heat transfer. But it is becoming close to the experimental results with increasing $\mathrm{Gr}_{\mathrm{x}}$. The difference at the beginning may be due to the influence of the prescribed initial conditions. At large $\mathrm{Gr}_{\mathrm{x}}$, results become independent of the initial profiles and the model gives better results. 



\section{CONCLUSIONS}

The low k- $\varepsilon$ model proposed by Yang and Shih is modified and applied to calculate turbulent buoyancy driven flow over a semiinfinite plate. By comparing the results with experimental results and results from Chien's model, it is shown that the model gives results with reasonable accuracy. Better results could be obtained by further refinement of the model.

Since the model constants used in this model are exactly the same as those in the standard $\mathrm{k}-\varepsilon$ model, away from the wall it reduces to the standard $k-\varepsilon$ model. Therefore this model could be used for both, the near wall turbulence and high Reynolds number turbulence. 

$a_{1}, a_{2}, a_{3} \quad$ Constants in the equation for damping function

$c_{\mathrm{k}}$

$c_{1 \varepsilon}, c_{2 \varepsilon}$

Constant in the equation for Kolmogorov time scale, 1.0

$\mathrm{c}_{\mu}$

$\mathrm{f}_{\mu}$

$\mathrm{g}$

Model constants

Coefficient in the equation for $v_{t}$

Damping function

Gravitational acceleration

$\mathrm{Gr}_{\mathrm{x}}$

Local Grashof number, $g \beta\left(t_{w}-t_{\infty}\right) x^{3} / v^{2}$

$\mathrm{k}$

Turbulent kinetic energy

$\mathrm{Nu}_{\mathrm{x}} \quad$ Local Nusselt number

$\mathrm{p}$

$\operatorname{Pr}$

Pressure

Prandtl number

$\mathrm{Pr}_{\mathrm{t}}$

$\mathrm{T}_{\mathrm{t}}$

Turbulent Prandtl number for $\mathrm{t}$

$\mathrm{T}_{\mathrm{k}}$

$\mathrm{t}$

Turbulent time scale

Kolmogorov time scale

Temperature

Wall temperature

$t_{w}$

$t_{\infty}$

U

$\mathrm{U}_{\mathrm{b}}$

$\mathrm{u}$

Free stream temperature

Characteristic velocity

Normalizing velocity, $\left(g \beta\left(t_{w}-t_{\infty}\right) v\right)^{1 / 3}$

Vertical velocity component

Velocity component perpendicular to the plate

Vertical coordinate

Horizontal coordinate

Coefficient of thermal expansion

Dissipation of kinetic energy

Density

Shear stress

$\sigma_{\mathrm{k}} \quad$ Turbulent Prandtl number for $\mathrm{k}$

$\sigma_{\varepsilon} \quad$ Turbulent Prandtl number for $\varepsilon$

$v \quad$ Kinematic viscosity

$v_{t} \quad$ Turbulent kinematic viscosity 



\section{REFERENCES}

1. Heindel, T. J., Ramadhyani, S. and Incropera, P., "Assessment of turbulence models for natural convection in an enclosure," Numerical heat transfer, Part B, 26, 1994, pp. 147-172.

2. Henkes, R. A. W. M. and Hoogendoorn, "Comparison of turbulence models for the natural convection boundary layer along a heated vertical plate," Int. J. Heat Mass Transfer, Vol. 32, No. 1, 1989, pp. 157169.

3. Kays, W. M. and Crawford, M. E., "Convective Heat and Mass Transfer," $3^{\text {rd }}$ Edition, McGraw-Hill Inc., New York, 1993.
4. Kuei-Yuan Chien, "Predictions of channel and boundary layer flows with a low Reynolds number turbulence model," AIAA Journal, Vol. 20, 1982, pp. 33-38.

5. Tsuji, T. and Nagano, Y., "Characteristics of a turbulent natural convection boundary layer along a vertical flat plate," Int. J. Heat Mass Transfer, Vol. 31, No. 8, 1988, pp. 1723-1734.

6. Yang, Z. and Shih, T. H., "A new time scale based $k-\varepsilon$ model for near wall turbulence," NASA Technical Memorandum 105768, Sept. 1992. 


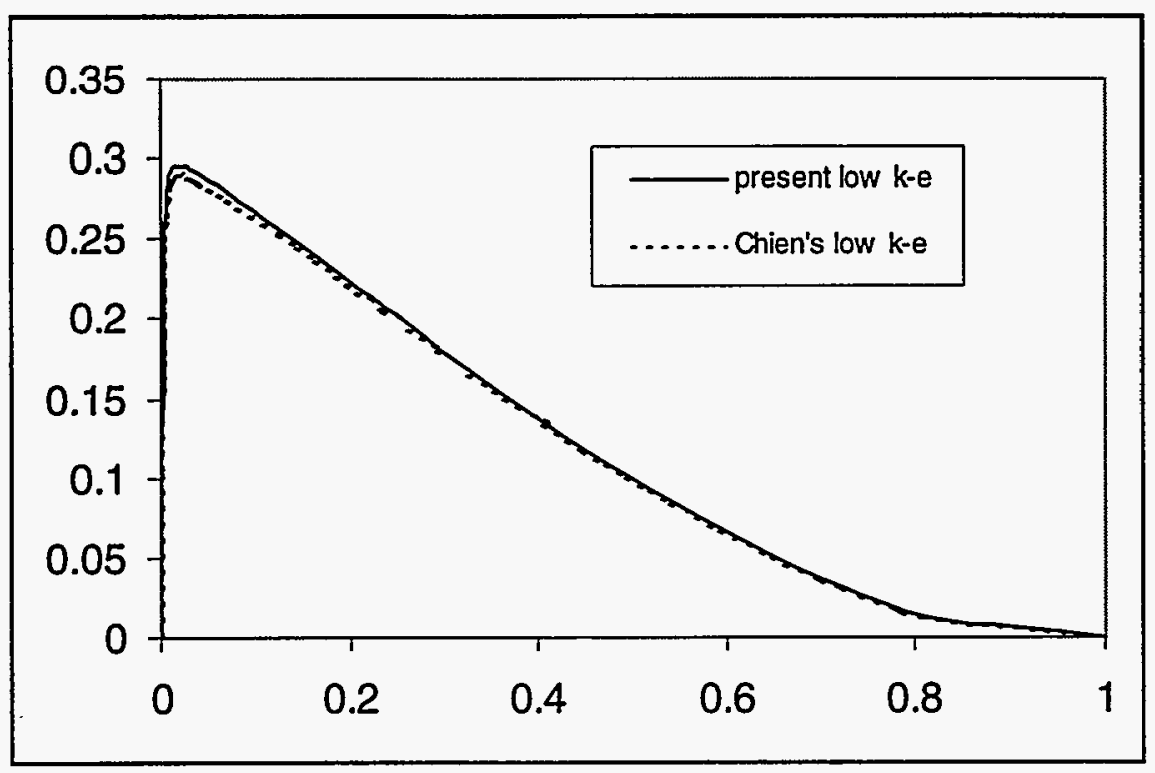

Figure 1: Velocity Profile at $\mathrm{Gr}_{\mathrm{x}}=10^{12}$ (Variation of $\mathrm{u} / \mathrm{U}$ with $\eta$ )

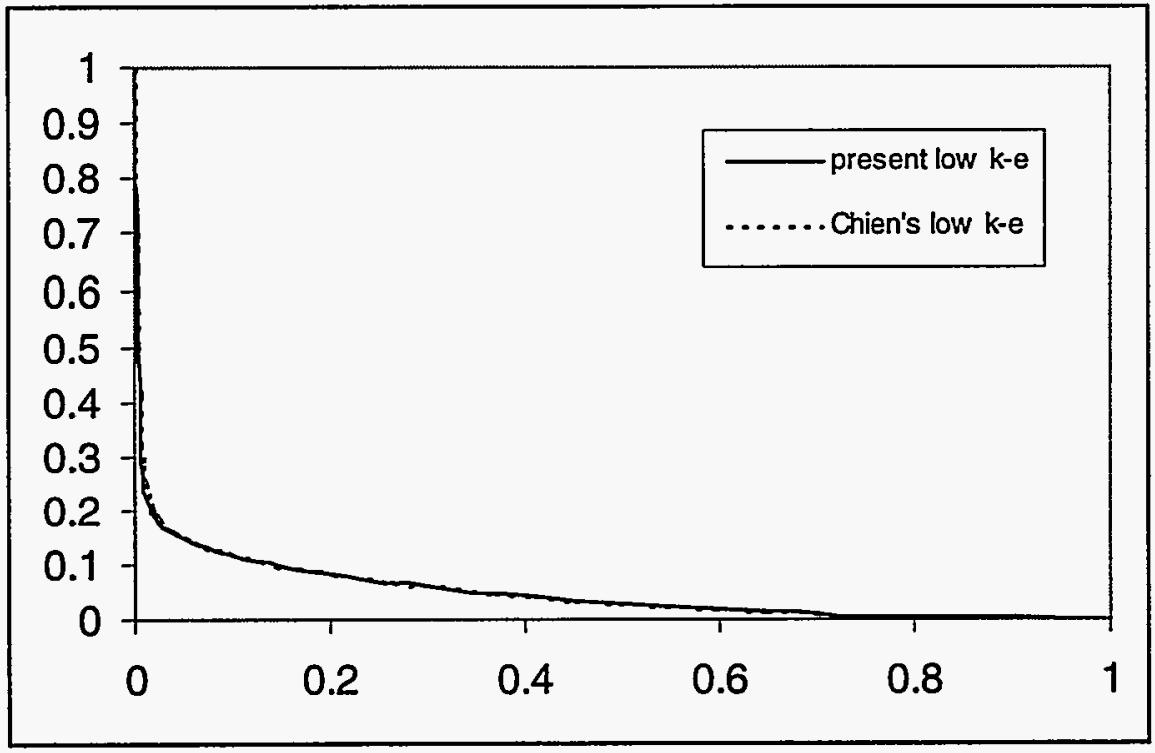

Figure 2: Temperature Profile at $\mathrm{Gr}_{\mathrm{x}}=10^{12}$ (Variation of $\left(t-t_{\infty}\right) /\left(\mathrm{t}_{w}-\mathrm{t}_{\infty}\right)$ with $\eta$ ) 


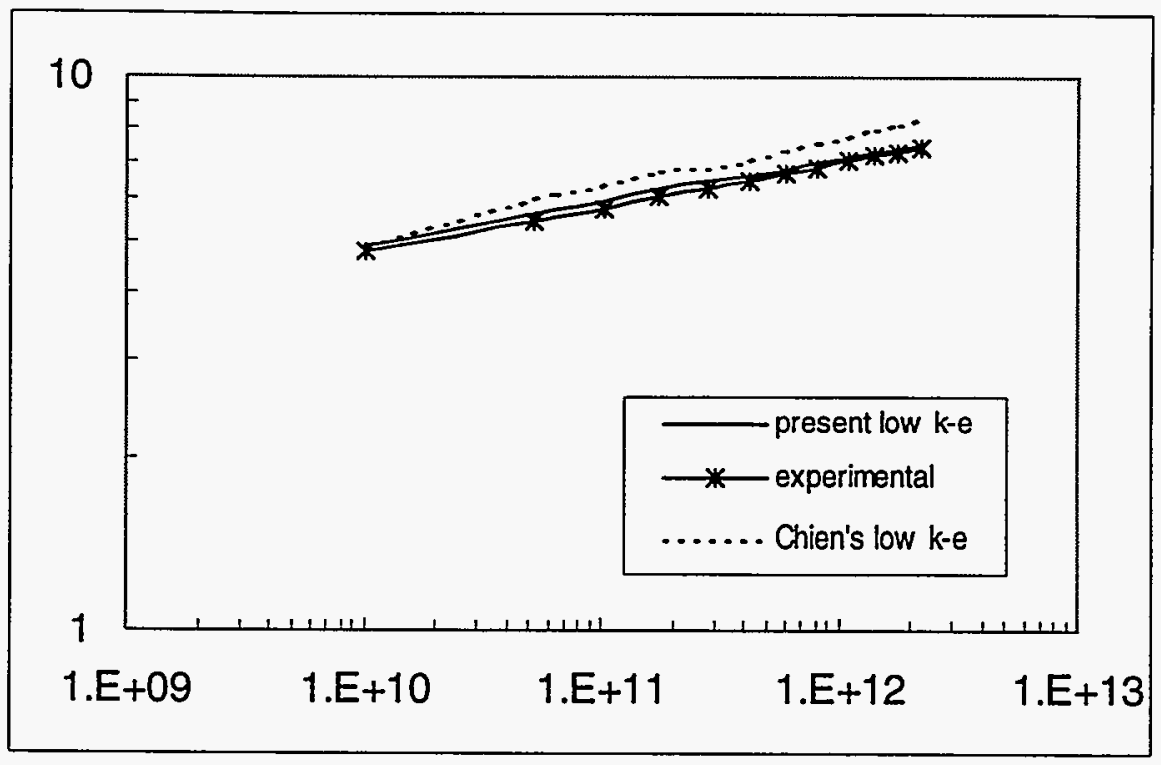

Figure 3: Wall Shear Stress (Variation of $\tau_{\mathrm{w}} / \rho \mathrm{U}_{\mathrm{b}}{ }^{2}$ with $\mathrm{Gr}_{\mathrm{x}}$ )

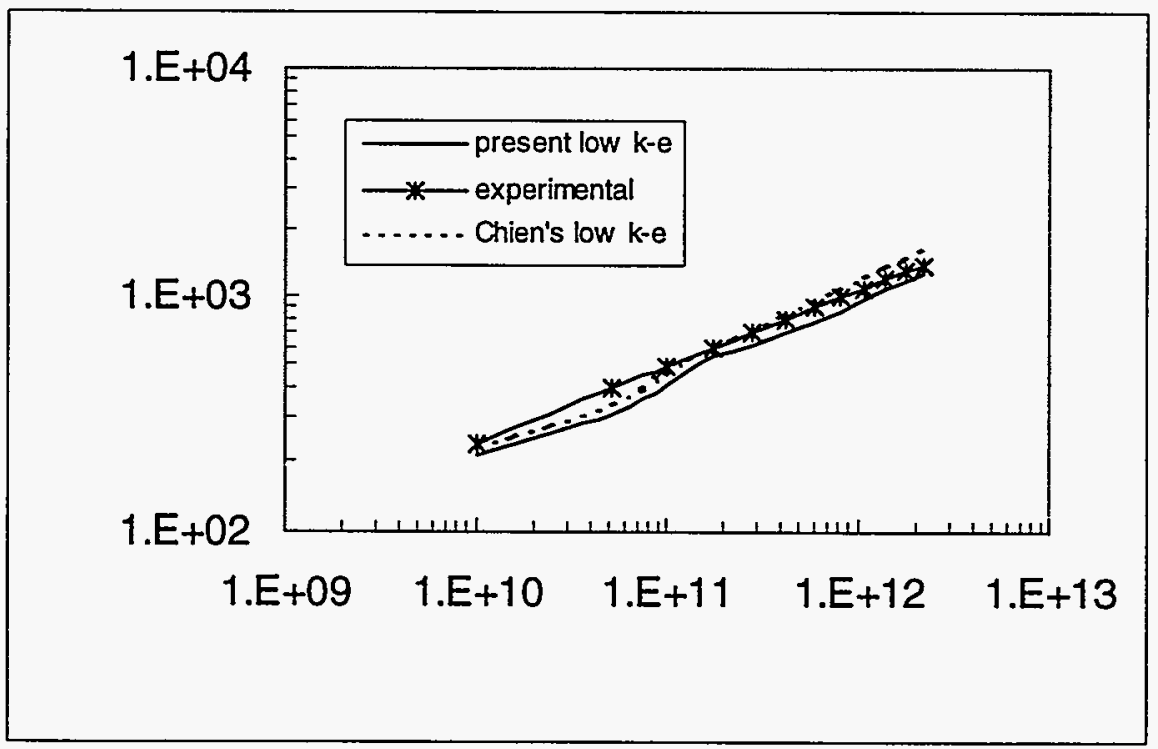

Figure 4: Wall Heat Transfer (Variation of $\mathrm{Nu}_{\mathrm{x}}$ with $\mathrm{Gr}_{\mathrm{x}}$ ) 